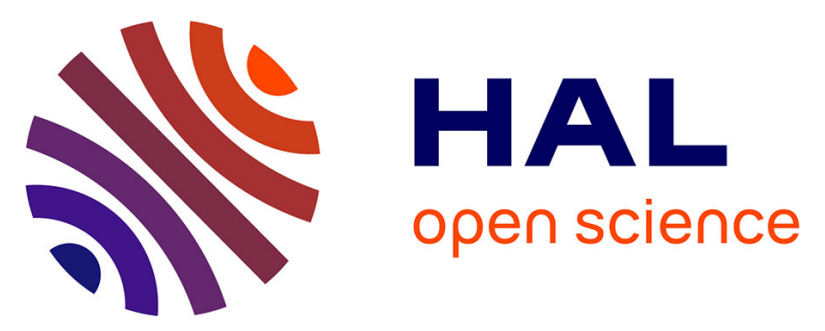

\title{
Airborne lidar observation of mountain-wave-induced polar stratospheric clouds during EASOE
}

Sophie Godin, Gérard Mégie, Christine David, D. Haner, C. Flesia, Y. Emery

\section{To cite this version:}

Sophie Godin, Gérard Mégie, Christine David, D. Haner, C. Flesia, et al.. Airborne lidar observation of mountain-wave-induced polar stratospheric clouds during EASOE. Geophysical Research Letters, 1994, 21 (13), pp.1335-1338. 10.1029/93GL02894 . hal-03038798

\section{HAL Id: hal-03038798 \\ https://hal.science/hal-03038798}

Submitted on 3 Feb 2021

HAL is a multi-disciplinary open access archive for the deposit and dissemination of scientific research documents, whether they are published or not. The documents may come from teaching and research institutions in France or abroad, or from public or private research centers.
L'archive ouverte pluridisciplinaire HAL, est destinée au dépôt et à la diffusion de documents scientifiques de niveau recherche, publiés ou non, émanant des établissements d'enseignement et de recherche français ou étrangers, des laboratoires publics ou privés. 


\title{
Airborne lidar observation of mountain-wave- induced polar stratospheric clouds during EASOE
}

\author{
S. Godin, G. Mégie, C. David, and D. Haner \\ Service d'Aéronomie du CNRS - Université Pierre et Marie Curie
}

\section{Flesia and Y. Emery}

Observatoire de Neuchâtel, Switzerland

Abstract. The airborne backscatter lidar Leandre was flown during the EASOE campaign on board the French ARAT-Fokker 27, to provide mesoscale observations of scattering layers in the stratosphere. The use of crosspolarization channels at the $532 \mathrm{~nm}$ laser emitted wavelength, allowed discrimination between the quasi-spherical particles of the Pinatubo aerosol and the non-spherical frozen particles of polar stratospheric clouds. Measurements taken on December $11^{\text {th }} 1991$ revealed mountain-wave-induced polar stratospheric clouds at $21 \mathrm{~km}$ altitude, extending over 300 $\mathrm{km}$ west and $300 \mathrm{~km}$ east from Kiruna. The wavelength and amplitude of the perturbation imply local cooling ranging from $3^{\circ} \mathrm{K}$ to $10^{\circ} \mathrm{K}$ in the stratosphere, taking the temperature below the threshold of formation of polar stratospheric clouds.

\section{Introduction}

One of the main scientific objectives of the European Arctic Stratospheric Ozone Experiment (EASOE) was to study the formation of polar stratospheric clouds and their influence on local ozone depletion in the arctic stratosphere. Such clouds are thought to be formed when the air temperature drops below a threshold, which for typical values of the water vapor and nitric acid mixing ratios of $5 \mathrm{ppm}$ and $10 \mathrm{ppb}$ respectively, is equal to $195^{\circ} \mathrm{K}$ at an altitude of $20 \mathrm{~km}$ or on the $50 \mathrm{hPa}$ pressure level (Toon et al., 1986). Processes such as orographically forced waves propagating into the stratosphere provide a mechanism for locally cooling the stratosphere, allowing PSC formation, although the average temperature as observed from radiosoundings or as calculated along isobaric or isentropic surface levels can be higher than the threshold value. The limited vertical and horizontal resolutions of the trajectories calculated from ECMWF analyses prevent the determination of such localised coolings. Observations and simulations of orographic waves in Antarctica have been reported by Bacmeister et al., 1990 and Cariolle et al., 1989. In northern Scandinavia, the mountains located west of Kiruna close to the Norwegian border $\left(68^{\circ} \mathrm{E}\right)$ have a crest height of about $1500 \mathrm{~m}$ and an horizontal extension of about $120 \mathrm{~km}$ in the west-east direction. Strong westerly winds blowing from the North Sea can force orographic waves (Volkert and Intes, 1992).

Copyright 1994 by the American Geophysical Union.

Paper number 93GL02894

0094-8534/94/93GL-02894\$03.00
As part of the ELSA project (Expériences Lidar dans la Stratosphère Arctique, Godin et al., 1992), the airborne backscatter lidar LEANDRE (Pelon et al., 1990) was flown during the EASOE campaign from Kiruna airport $\left(68^{\circ} \mathrm{N}\right.$, $22^{\circ} \mathrm{E}$ ). As the dual wavelength, dual polarization lidar LEANDRE is designed to observe the three dimensional structure and optical properties of scattering layers in the atmosphere, the objective of this experiment was the measurement of polar stratospheric clouds. The injection of aerosols into the stratosphere by the major eruption of Mount Pinatubo in the Philippines in June 1991 made it important to study the evolution of the aerosol layers in the lower stratosphere.

\section{Experimental system and campaign operation}

The two wavelengths emitted by the LEANDRE instrument are the fundamental (1064 $\mathrm{nm}$ ) and second harmonic $(532 \mathrm{~nm})$ emissions of a Nd:YAG laser, the respective output energies being $100 \mathrm{~mJ}$ and $25 \mathrm{~mJ}$. At 532 $\mathrm{nm}$, the cross-polarized backscattered signal is also recorded, allowing thus the differentiation between spherical and nonspherical scatterers in the atmosphere. The lidar signals are received on a $30 \mathrm{~cm}$ diameter telescope and detected using photomultiplier tubes for the visible wavelength and a photodiode in the near infrared. The signal is time-resolved using a waveform transient recorder and the data are stored on magnetic tapes for further analysis. Real time visualization of the signals is available during the flight. The instrument is carried by the French ARAT-Fokker 27 (Avion de Recherche Atmosphérique et de Télédétection). During the EASOE campaign the instrument was operated in the zenith looking mode, where the direction of the emitted beam makes a $20^{\circ}$ angle with the zenith. Besides, only the two cross-polarized signals at $532 \mathrm{~nm}$ were used. The ARAT was operated from Kiruna airport. The average flight altitude was between 4 and $5.5 \mathrm{~km}$ and the maximum horizontal range (one way) was of the order of $350 \mathrm{~km}$. Thus only mesoscale observations were possible, following 3 different flight paths :

- westward from Kiruna to Narvik and the North Sea, the main interest of which was the possibility to observe upwind and downwind of the mountains,

- eastward from Kiruna to Sodankylä and close to the Finnish border, the main interest of which was the possibility of performing measurements close to the ground-based backscatter lidar which had been installed at Sodankylä for the ELSA project (Stefanutti et al.,1992),

- northward from Kiruna to Hammerfest, the main interest of which being the possibility of a deeper penetration into the polar vortex. 
During the EASOE campaign, the LEANDRE instrument was flown intensively during two observation periods :

(1) 10 flights were made from 2 December to 14 December 1991 for a total of 31 flight hours,

(2) 20 flights were made from 14 January to 17 February 1992 , for a total of 47 flight hours.

In all 30 flights the system operated successfully. Flight operation of the instrument was only precluded during the period of January 22 to January 28 , due to a laser failure, and from February 10 to 14 due to aircraft-related problems.

\section{Observation of the Pinatubo aerosol cloud}

Volcanic aerosol layers between altitudes of 15 and 20 $\mathrm{km}$ were seen on all flights. Furthermore, the altitude of the layers varied from one flight to another, in association with the movement of the polar vortex from day to day (Neuber et al., 1993, this issue). An example of the backscatter and depolarization ratios of these aerosols is shown in figure 1 , for the February $4^{\text {th }}$ flight. The backscatter ratio is calculated from the parallel-polarized channel signal : $R_{p}=\beta_{p} / \beta_{m p}$ where $\beta_{\mathrm{p}}$ and $\beta_{\mathrm{mp}}$ correspond to the total and molecular backscatter coefficients respectively, related to the parallel polarization. This ratio is corrected for aerosol extinction, according to the Klett method (Klett, 1981). The molecular backscatter coefficient is calculated using the pressuretemperature profiles obtained from the radiosoundings performed in Kiruna. It is assumed to be uniform along the flight path. A value of $4 \%$ is used for the Rayleigh depolarization. The depolarization ratio is defined as $\beta_{p} /\left(\beta_{s}+\beta_{p}\right)$ where $\beta_{p}$ and $\beta_{s}$ correspond to the total backscatter coefficient on the parallel and perpendicular channel respectively. In all LEANDRE measurements performed during EASOE, the depolarization ratio in the main aerosol cloud was found to be lower than $4 \%$. This is consistent, if we take into account the error bar on this ratio, with the virtual absence of non-spherical particles. Higher values of depolarization, on the order of $6 \%$, are often found at the base of the cloud, at altitudes from 8 to $14 \mathrm{~km}$, indicating the presence of non-spherical particles. These
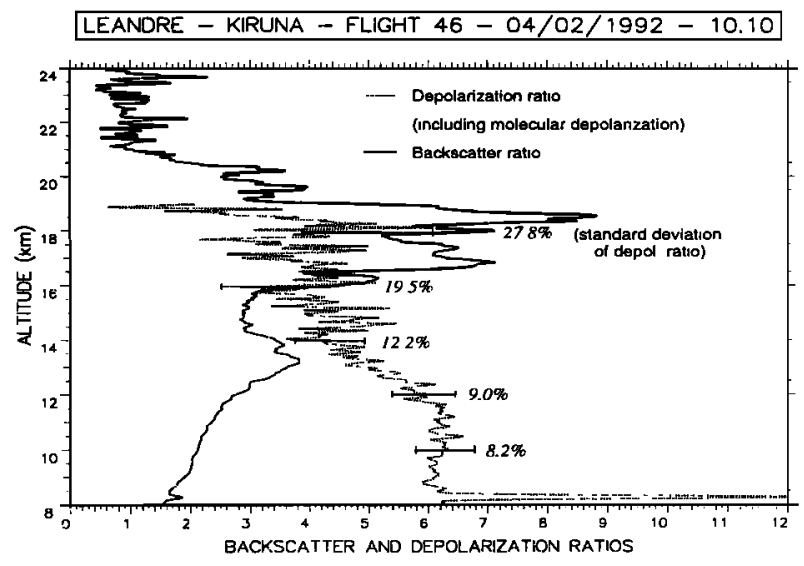

Figure 1 : Backscatter ratio and depolarization ratio as measured by Leandre on the $4^{\text {th }}$ of February 1992. Error bars on the depolarization ratio correspond to $1 \sigma$ standard deviation. results are in agreement with those obtained at many groundbased lidar stations (Stefanutti et al., this issue). For depolarization ratios larger than those values, the presence of polar stratospheric clouds can be assumed.

\section{Moutain wave induced PSC on December 11, 1991}

Flights 29 and 30 , made on the $11^{\text {th }}$ of December, following the westward and eastward paths respectively, revealed large oscillations in the scattering layers as seen in figure 2, which shows the backscatter ratio measured on the parallel polarized channel during both flights as a function of the distance to Kiruna Airport. It is a cross-section of the backscatter ratio of the aerosols located between the North Sea and Sodankylä on that day. Note that the two flights were made respectively from 8 to $10 \mathrm{UT}$ and from 13 to 15:30 UT. The wave activity is present throughout the region scanned by the lidar, with marked differences in the horizontal and vertical patterns, according to the distance from the Norwegian mountains. In particular, on both flights, the amplitude of the wave increased just downwind from the relief, with the air rising through about $1 \mathrm{~km}$. The horizontal wavelength was about $33 \mathrm{~km}$ upwind and $50 \mathrm{~km}$ downwind of the mountains, and the vertical amplitude was on average 250 meters. The radiosounding performed at noon on that day from Bodo (located on the Norwegian coast) showed a jet of $36 \mathrm{~m} / \mathrm{s}$ at the tropopause, sufficient for the development of orographic waves in the stratosphere (figure 3). This wave activity was also detected on ozone and water vapor ballon borne measurements performed on the same day, that showed a gravity wave with a vertical wavelength of $10 \mathrm{~km}$ (Teitelbaum et al., this issue). On figure 2, we see a distinct scattering layer located at about $21 \mathrm{~km}$. This layer is also seen on the measurements made by a backscatter sonde launched from Kiruna, in the afternoon. Figure 4 presents a comparison of the aerosol backscatter ratio obtained by Leandre and the backscatter sonde, at different wavelengths. Despite a few hundred metres off-set in the height of the upper scattering layer as measured by Leandre, can be attributed to the different location of the measurements and to the oscillations in the scattering layers, there is a good correspondance between the three profiles. The vertical profile of the depolarization ratio obtained during the afternoon flight is displayed in figure 5 , together with the backscatter ratio. The upper layer shows a depolarization ratio of more than $40 \%$, giving direct evidence for the presence of non-spherical particles, distinct from the main Pinatubo aerosols which have been reported during the Arctic campaign to be spherical with an average size of $0.2-0.3 \mu \mathrm{m}$ (Stein et al., this issue). This PSC was also observed from Sodankylä by the backscatter lidar, but the value of the Rayleigh corrected depolarization ratio measured at $532 \mathrm{~nm}$ around 12 UT was only about $10 \%$ (Stein et al., this issue). Coincident measurements were not possible, due to the poor meteorological conditions in Sodankylä on that day. Further microphysical studies taking into account the time difference between the two measurements are needed to understand this discrepancy. The presence of a polar stratospheric cloud at this altitude is consistant with the temperature measurements at Bodo (figure 3) and Sodankylä, which were, above $20 \mathrm{~km}$, slightly under the threshold of formation of NAT particles, 


\section{LEANDRE - KIRUNA : BACKSCATTER RATIO FLIGHTS 29 AND $30-11 / 12 / 1991$}

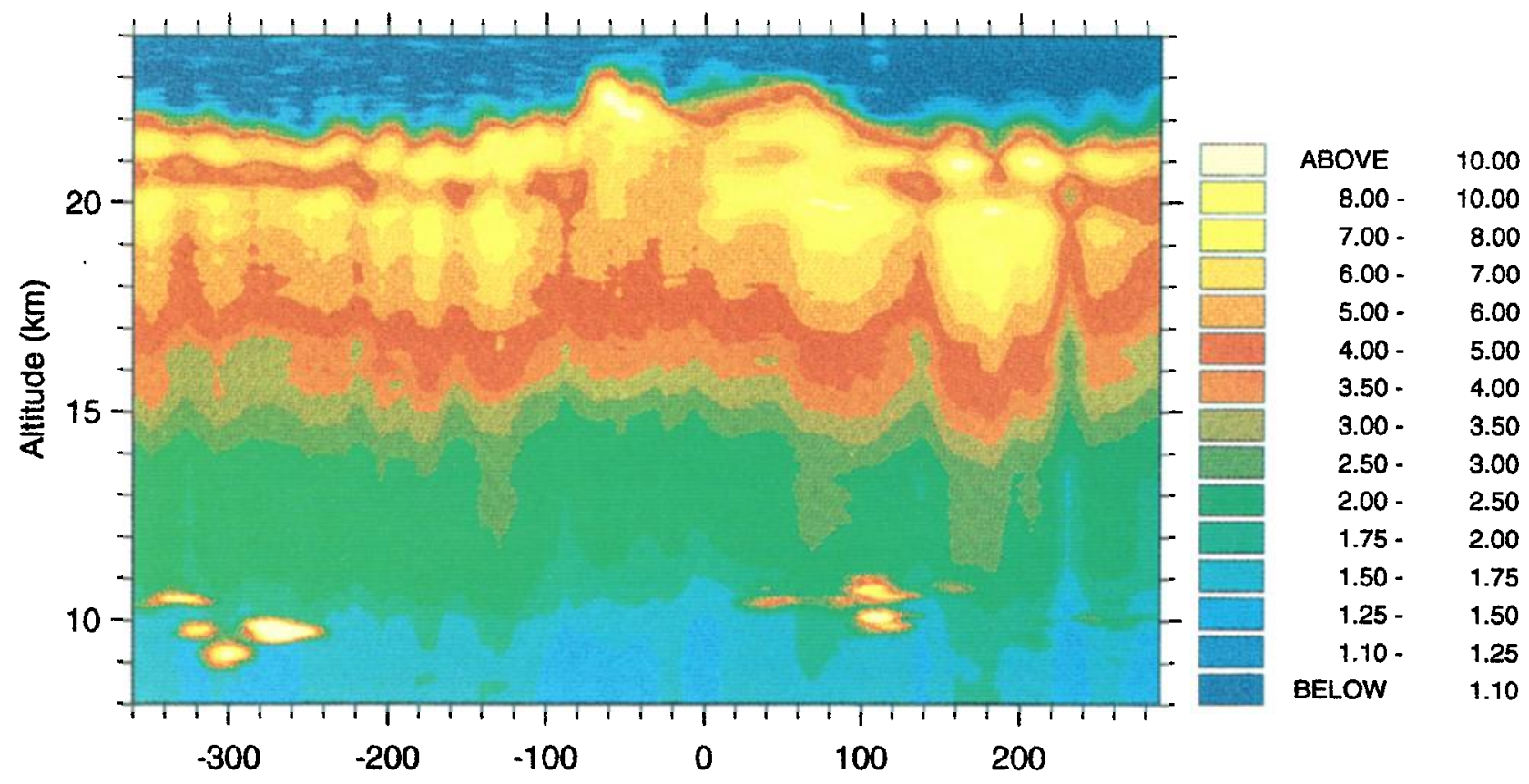

Distance from Kiruna Airport (km)

Figure 2 : Backscatter ratios measured during flights 29 and 30 on the $11^{\text {th }}$ of December 1991.

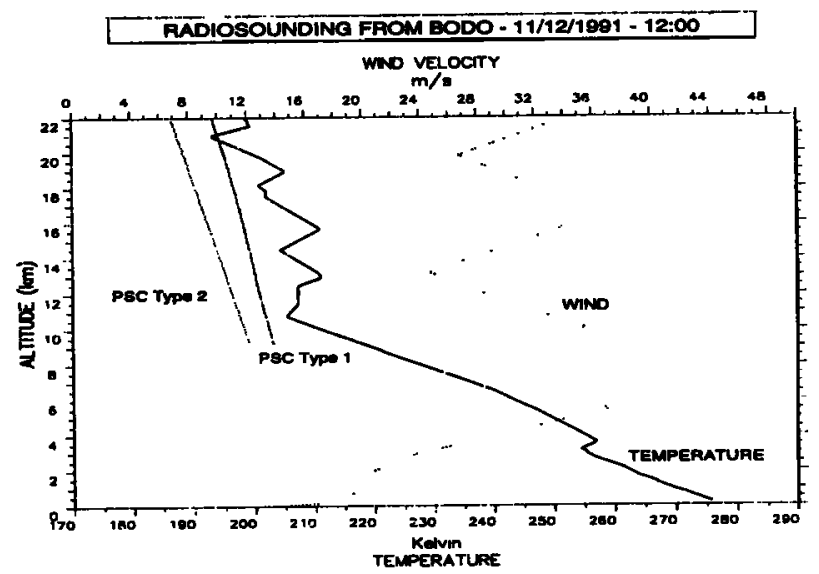

Figure 3 : Temperature and wind radiosounding measurements from Bodo on December $11^{\text {th }} 1991$. Temperature thresholds for the formation of PSC of type 1 (NAT) and type 2 (ice) are also indicated.

considering an average HNO3 profile provided. by the EASOE database and an average water vapor mixing ratio of 5 ppmv. According to Leandre measurements, the amplitude of the mountain wave should have induced adiabatic coolings ranging from $2.5^{\circ} \mathrm{K}$ to $10^{\circ} \mathrm{K}$ just downwind of the mountains. As the synoptic situation shows that northern Scandinavia was inside the vortex on that day with minimum temperature of $198^{\circ} \mathrm{K}$ on the $550 \mathrm{~K}$ potential temperature surface, the gravity wave was probably responsible for the formation of the polar stratospheric cloud observed by Leandre.

\section{Conclusion}

The different results presented here show that the backscatter airborne lidars can detect mesoscale dynamical

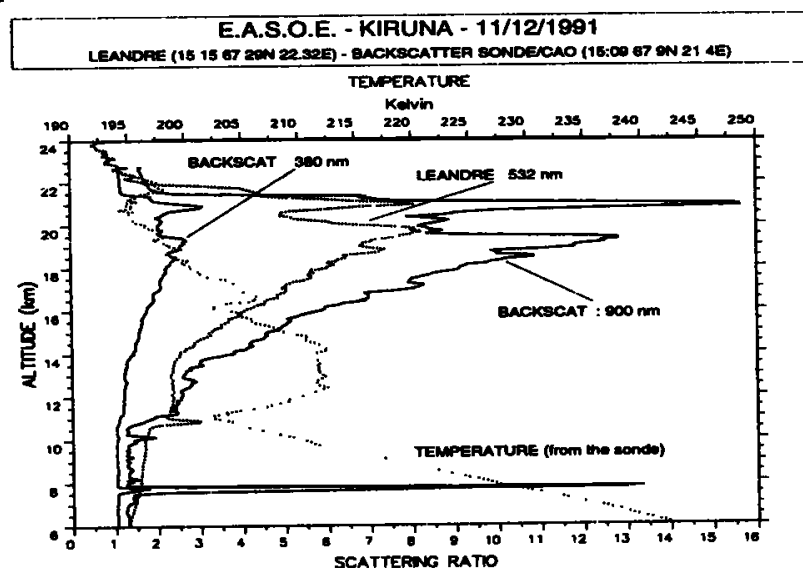

Figure 4 : Comparison of backscatter ratio obtained by Leandre and the balloon borne backscatter sonde launched from Kiruna on December $11^{\text {th }} 1991$

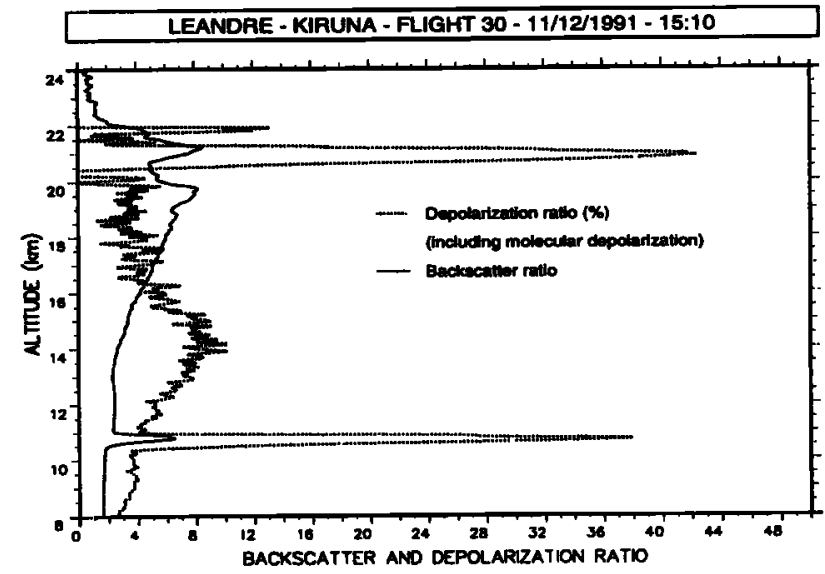

Figure 5 : Depolarization ratio and backscatter ratio measured by Leandre during flight 30 
processes. Stratospheric mountain waves in Northern Scandinavia can have a significant impact on the formation of polar stratospheric clouds, taking into account the average meteorological conditions of that region. Careful study using microphysical models of the event of December $11^{\text {th }} 1991$, which lasted several hours and was well observed, should make it possible to assess the potential for ozone destruction of such processes during the Arctic winter.

Acknowledgements. This study has been jointly supported by the Commission of the European Communities DG XII under contract No. STEP-CT91-040, and by the French Middle Atmosphere Programme. The authors want to specially acknowledge the invaluable support of the IGN (Institut National Geographique) aircraft crew, and of the INSU ARAT team.

\section{References}

Bacmeister J.T., M.R. Schoerbel, L.S. Lait, P.A. Newman, B. Gray : ER-2 mountain wave encounter over Antarctica, evidence for blocking. Geophys. Res. Lett., 17, 81-84, 1990.

Cariolle, D., S. Muller, F. Cayla and M.P. Mc Cormick : Mountain waves, polar stratospheric clouds, and the ozone depletion over Antarctica, J. Geophys. Res. 94, No D9, 11233-11240, 1989.

Godin, S., G. Mégie, C. David, V. Mitev, Y. Emery, C. Flesia, V. Rizi, G. Visconti, L. Stefanutti: Ozone, aerosols and polar stratospheric clouds measurements during the EASOE campaign, Proc. Quadr. Ozone Symposium, 1992.

Klett J.D. : Stable analytical inversion solution for processing lidar returns, Applied Optics, 20, 2, 1981.

Neuber R., G. Beyerle, G. Fiocco, A. Di Sarra, K.H.Fricke,
C. David, S. Godin, L. Stefanutti, G. Vaughan, J.P. Wolf : Latitudinal distribution of stratospheric aerosols durind the EASOE winter 1991/92, this issue

Stefanutti L., F. Castagnoli , M. Del Guasta, M. Morandi, V.M. Sacco, V. Venturi, L. Zuccagnoli, J. Kolenda, H. Kneipp, P. Rairoux, B. Stein, D. Weidauer, J.P. Wolf, L. Woste, C. Flesia, R. Matthey, S. Godin : Arctic Polar Stratospheric Cloud measurements by means of a four wavelength depolarization backscatter lidar, Proc. Quadr. Ozone Symposium, 1992

Stefanutti L., T. Peter, M. Del Guasta, S. Godin, M. Morandi, B. Stein, P. Rairoux, J.P. Wolf : Depolarization lidar returns from the lower stratosphere over Sodankylä during EASOE, this issue.

Stein B., M. Del Guasta, J. Kolenda, M. Morandi, P. Rairoux, L. Stefanutti, J.P. Wolf : Stratospheric aerosols size distribution from multispectral lidar measurements at Sodankylä during EASOE, this issue

Teitelbaum H., J. Ovarlez, H. Kalder, S. Loth : Some observations of gravity-waves-induced structures in ozone and water vapor during the EASOE, this issue

Toon, O.B., P. Hamill, R.P. Turco, J. Pinto : Condensation of $\mathrm{HNO}_{3}$ and $\mathrm{HCl}$ in the winter polar stratospheres, Geophysical Res. Lett., 1986

Volkert, H. and D. Ines: Orographically forced stratospheric waves over Northern Scandinavia, Geophys. Res. Lett., 1992.

S. Godin, G. Mégie, C. David, D. Haner : Service d'Aéronomie du CNRS, Université Pierre et Marie Curie, Boîte 102, 4 place Jussieu, 75252 Paris Cédex 05, France

C. Flesia, Y. Emery : Observatoire de Neuchâtel, Neuchâtel, Switzerland

(Received : November 16, 1992 Revised : April 5, 1993 Accepted : October 14, 1993) 